01.1;09.5;15

\title{
Малогабаритный криотермостат с хладагентом из твердого диоксида углерода
}

\author{
( Д.Р. Деветьяров ${ }^{1}$, М.А. Ероньян ${ }^{1, \uparrow}$, В.Н. Ломасов ${ }^{2}$, А.Ф. Опалихин ${ }^{3}$, Ю.А. Скупов ${ }^{1}$, Б.А. Соболь ${ }^{1}$, \\ А.А. Унтилов ${ }^{1}$ \\ ${ }^{1}$ Концерн „Центральный научно-исследовательский институт „Электроприбор“, Санкт-Петербург, Россия \\ ${ }^{2}$ Санкт-Петербургский государственный политехнический университет Петра Великого, Санкт-Петербург, Россия \\ ${ }^{3} \mathrm{OOO}$ „Теста“, Санкт-Петербург, Россия \\ I E-mail: eronyan@mail.ru
}

Поступило в Редакцию 25 июля 2019г.

В окончательной редакции 25 июля 2019 г.

Принято к публикации 9 сентября 2019г.

\begin{abstract}
Предложена простая конструкция малогабаритного криотермостата для исследования влияния гаммаоблучения на оптические потери одномодовых фторсиликатных световодов на длине волны $1.31 \mu \mathrm{m}$. Обнаружено повышение их радиационной стойкости с понижением температуры испытаний от +25 до $-60^{\circ} \mathrm{C}$.
\end{abstract}

Ключевые слова: криотермостат, фторсиликатные световоды, радиационная стойкость, гамма-излучение, рассеяние.

DOI: 10.21883/PJTF.2019.24.48792.17999

Эксплуатируемые в космическом и воздушном околоземном пространстве объекты различного рода подвергаются воздействию радиации и температур менее $-50^{\circ} \mathrm{C}$. Повышение надежности функционирования оптоэлектронных систем таких объектов выдвигает требования к радиационным испытаниям их элементной базы при низких температурах. Особенно это относится к волоконным световодам (ВС), наиболее стойкими из которых являются оптические волокна с сердцевиной из чистого кварцевого стекла и оболочкой, легированной фтором [1-3]. Исследование влияния радиационного воздействия на ВС при температурах менее $-50^{\circ} \mathrm{C}$ возможно с использованием малогабаритных криостатов дроссельного типа [4]. Однако их сложная конструкция и необходимость электропитания затрудняют требуемое в ряде случаев ускоренное (за время не более $5 \mathrm{~s}$ ) перемещение криостатов с образцами в зону заданной лучевой нагрузки. Без потребления электрической энергии могут работать малогабаритные криостаты с использованием хладагентов. На рынке криостаты и криотермостаты такого типа в виде товарной продукции отсутствуют. В источниках научно-технической информации имеются весьма скудные сведения о подобного рода разработках.

Целью наших исследований является анализ работы простого по конструкции малогабаритного криотермостата на основе хладагента из твердого диоксида углерода (ТДУ), а также проведение радиационных низкотемпературных испытаний ВС.

На рис. 1 представлена принципиальная конструкция криотермостата с теплоизоляционной стенкой (ТC) из пенополистирола. Тепловой поток, затрачиваемый на испарение ТДУ 9, из окружающей воздушной среды проходит через ТС 2, рабочую камеру 3, блок термо- стабилизации 6 и терморегулирующий экран 7, толщина которого определяет температуру рабочей камеры. Ее термостабилизация обеспечивается стационарным тепловым потоком, затрачиваемым на сублимацию ТДУ. Отличительной особенностью криотермостата является наличие блока термостабилизации в виде массивного бруска из дюралюминиевого сплава (ДС), обеспечивающего за счет высокой теплопроводности однородность температурного поля рабочей камеры. В то же время его большая теплоемкость ослабляет влияние загружаемых образцов на температуру рабочей камеры.

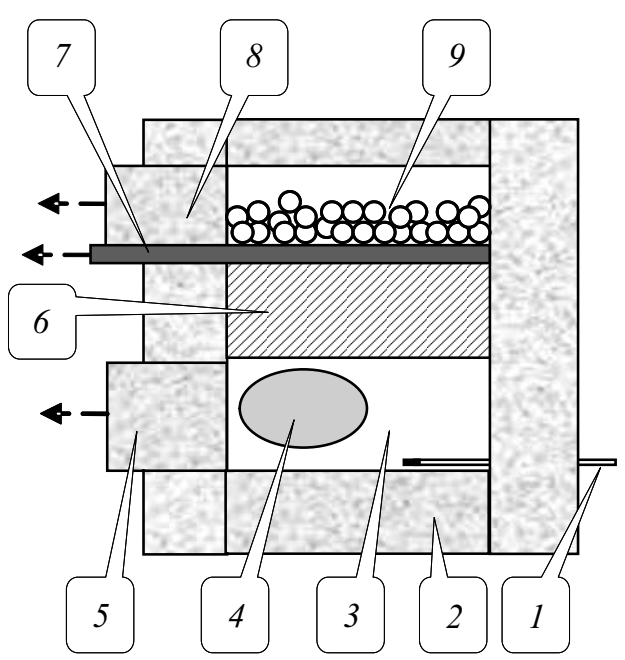

Рис. 1. Принципиальная конструкция малогабаритного криотермостата. 1 - термопара, 2 - наружная ТC, 3 - рабочая камера, 4 - испытываемый образец, 5 - крышка рабочей камеры, 6 - блок термостабилизации, 7 - терморегулирующий экран, 8 - крышка для загрузки хладагента, 9 - гранулы ТДУ. 
Параметры материалов криотермостата

\begin{tabular}{c|c|c|c}
\hline Параметр & $\begin{array}{c}\text { Пенополистирол } \\
\text { ПСБ-25 для ТС }\end{array}$ & $\begin{array}{c}\text { Пенополистирол } \\
\text { ПСБ-50 для экрана }\end{array}$ \\
\hline$\lambda, \mathrm{W} /(\mathrm{m} \cdot \mathrm{K})$ & 0.04 & 160 & 0.04 \\
$S, \mathrm{~m}^{2}$ & 0.05 & 0.029 & 0.029 \\
$\delta, \mathrm{m}$ & 0.05 & 0.05 & $0-0.04$
\end{tabular}

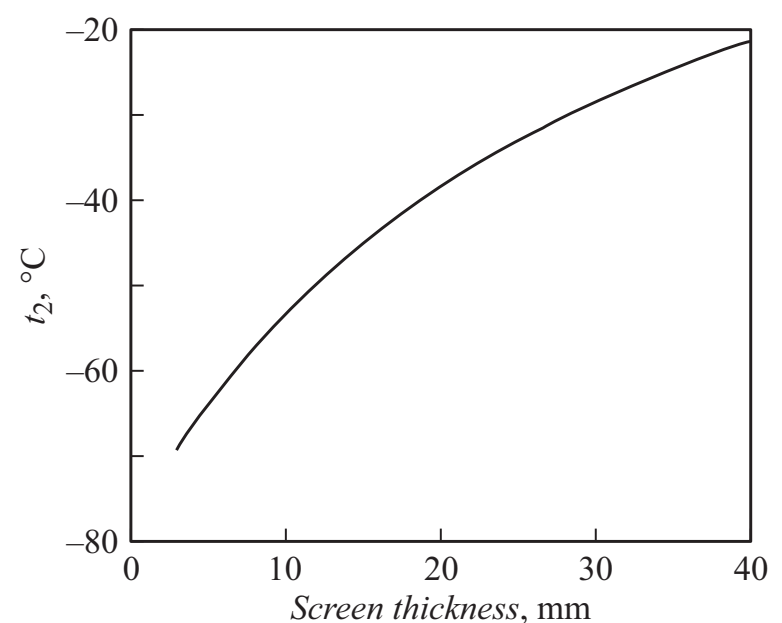

Рис. 2. Расчетная зависимость температуры рабочей камеры $\left(t_{2}\right)$ от толщины экрана.

Для определения влияния параметров малогабаритного криотермостата на температуру рабочей камеры были проведены теплотехнические расчеты одномерной задачи для постоянного стационарного теплового потока $(Q)$ через стенки, находящиеся в тепловом контакте [5]:

$$
\begin{aligned}
& Q=\lambda_{1}\left(S_{1} / \delta_{1}\right)\left(T_{1}-T_{2}\right), \\
& Q=\lambda_{2}\left(S_{2} / \delta_{2}\right)\left(T_{3}-T_{4}\right), \\
& Q=\lambda_{3}\left(S_{3} / \delta_{3}\right)\left(T_{4}-T_{5}\right),
\end{aligned}
$$

где $\lambda_{1}, S_{1}, \delta_{1} ; \lambda_{2}, S_{2}, \delta_{2} ; \lambda_{3}, S_{3}, \delta_{3}-$ коэффициенты теплопроводности, площадь и толщина слоя ТС, ДС и терморегулирующего экрана соответственно; $T$ - температура на границах окружающая атмосфера-ТC $\left(T_{1}\right)$, TC-атмосфера рабочей камеры $\left(T_{2}\right)$, атмосфера рабочей камеры-ДС $\left(T_{3}\right)$, ДС-экран $\left(T_{4}\right)$, экран-ТДУ $\left(T_{5}\right)$.

Их совместное решение дает в неявном виде зависимость $T_{2}$ от $\delta_{3}$

$$
T_{2}=\frac{C_{1} T_{1}\left(C_{3}+C_{2}\right) / C_{2}+C_{3} T_{5}}{\left(C_{1}+C_{2}\right)\left(C_{3}+C_{2}\right) / C_{2}-C_{2}}
$$

где $C_{i}$ равно $\lambda_{i} S_{i} / \delta_{i}$.

Расчеты основываются на следующих допущениях: - $T_{1}$ равна температуре окружающей среды $(293 \mathrm{~K})$; - $T_{3}$ равна $T_{2}$ благодаря высокой эффективности конвективного теплообмена в воздушной среде рабочей камеры;
- $T_{5}$ определяется температурой сублимации ТДУ $(195 \mathrm{~K})$;

- при определении $S_{1}$ учитывалась вся поверхность пенополистирола рабочей камеры.

Экспериментальный образец криотермостата с габаритами $300 \times 300 \times 300 \mathrm{~mm}$ имел объем рабочей камеры $1100 \mathrm{~cm}^{3}$ и массу ДС $\sim 4 \mathrm{~kg}$.

На основании заимствованных из справочной литературы данных о свойствах материалов криотермостата (см. таблицу) и уравнения (4) была рассчитана зависимость температуры рабочей камеры от толщины теплоизоляционного экрана (рис. 2).

Результаты испытания криотермостата хорошо согласуются с расчетными данными: при толщине теплового экрана $7 \mathrm{~mm}$ температура рабочей зоны была на уровне $-60^{\circ} \mathrm{C}$.

Для радиационных испытаний были изготовлены образцы одномодовых ВС с сердцевиной из чистого кварцевого стекла и фторсиликатной оболочкой известным методом модифицированного химического парофазного осаждения [1]. В отличие от этого способа фторсиликатная оболочка наносилась двухстадийным методом, а в процессе высокотемпературного сжатия заготовки ее внутренний канал продувался азотом, содержащим не более $1 \cdot 10^{-5} \operatorname{mass} \%$ влаги. Длина волны отсечки высшей моды $\mathrm{LP}_{11}$ соответствовала $1.2 \mu \mathrm{m}$.

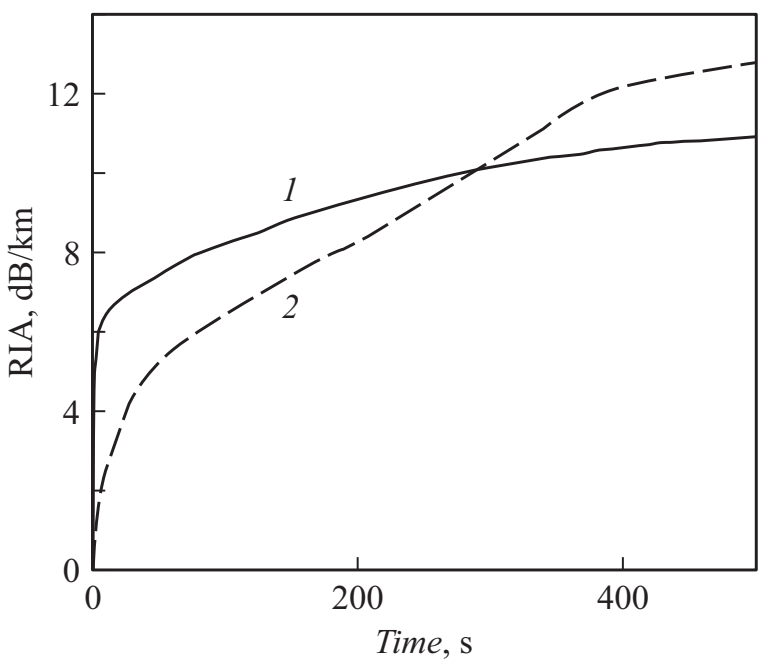

Рис. 3. Влияние длительности гамма-облучения ВС мощностью $1 \mathrm{~Gy} / \mathrm{s}$ на наведенные в нем оптические потери (RIA) на длине волны $1.31 \mu$ m при температуре -60 (1) и $+25^{\circ} \mathrm{C}(2)$. 
Загрузка в рабочую камеру криотермостата для радиационных испытаний намотанного в бухту ВС длиной $100 \mathrm{~m}$ и массой $8 \mathrm{~g}$ привела к временному повышению температуры от -60 до $-57^{\circ} \mathrm{C}$. Конструкция криотермостата позволила ускоренно вводить испытываемый образец ВС в необходимую энергетическую зону облучения и обеспечивать температуру испытаний $-60^{\circ} \mathrm{C}$.

Метод измерения наведенных радиацией оптических потерь заключался в измерении ослабления излучения, прошедшего через $\mathrm{BC}$, в процессе его облучения на установке К-120000. В удаленной от источника гаммаизлучения ${ }^{60} \mathrm{Co}$ зоне радиационного воздействия мощность облучения ВC составляла $1 \mathrm{~Gy} / \mathrm{s}$. Зондирующее излучение с длиной волны $1.31 \mu \mathrm{m}$ в оптическом тестере EXFO FOT-600 перед вводом в ВС ослаблялось до $5 \mu \mathrm{W}$. Эта величина является пороговым уровнем, выше которого возможно фотообесцвечивание радиационных дефектов [6]. Измерения при температуре $-60^{\circ} \mathrm{C}$ проводились при ускоренном вводе образца с криотермостатом в зону облучения (не более $4 \mathrm{~s}$ ), в то время как испытания при комнатной температуре осуществлялись в штатном режиме введения излучателя в зону облучения.

Увеличение наведенных радиацией оптических потерь с температурой $\mathrm{BC}$ на завершающем этапе процесса облучения (рис. 3) может свидетельствовать о вкладе высокой энергии колебаний атомов в процесс образования дефектов, приводящих, как установлено в работе [2], к рассеянию излучения в длинноволновой области прозрачности кварцевого стекла.

Таким образом, результаты анализа работоспособности простого по конструкции малогабаритного криотермостата, функционирующего на основе хладагента из ТДУ, свидетельствуют о возможности его использования для радиационного испытания образцов ВС при низких температурах вплоть до $-70^{\circ} \mathrm{C}$.

\section{Конфликт интересов}

Авторы заявляют, что у них нет конфликта интересов.

\section{Список литературы}

[1] Kashaykin P.F., Tomashuk A.L., Dianov E.M., Nishchev K.N., Salgansky M.Y., Abramov A.N., Guryanov A.N. // J. Lightwave Technol. 2015. V. 33. N 9. P. 1788-1793. DOI: $10.1109 /$ JLT.2015.2394806

[2] Bisyarin M.A., Dukelskiy K.V., Eronyan M.A., Komarov A.V., Lomasov V.N., Meshkovskiy I.K., Reutsky A.A., Shcheglov A.A., Ustinov S.V. // Mater. Res. Express. 2019. V. 6. N 2. P. 026202. https://iopscience.iop.org/article/10.1088/2053-1591/aaec3f

[3] Tomashuk A.L., Levchenko A.E., Dianov E.M., Filippov A.V., Moiseenko A.N., Bychkova E.A., Tatsenko O.M., Zavialov N.V., Grunin A.V., Batova E.T., Salgansky M.Y., Guryanov A.N., Kashaykin P.F., Azanova I.S., Tsibinogina M.K. // J. Lightwave Technol. 2017. V. 35. N 11. P. 2143-2149. DOI: $10.1109 / J L T .2016 .2623359$
[4] Архаров А.М., Марбенина И.В., Микулин Е.И. Криогенные системы. Основы теории и расчета. М.: Машиностроение, 1996. T. $1.576 \mathrm{c}$.

[5] Крейт Ф., Блэк У. Основы теплопередачи. Пер. с англ. М.: Мир, 1983. $513 \mathrm{c}$.

[6] Долгов И.И., Иванов Г.А., Чаморовский Ю.К., Яковлев М.Я. // Фотон-экспресс. 2005. № 6. С. 4-10. 